\title{
DE CRYNSSENHERDENKING IN 1917
}

DOOR

FRED. OUDSCHANS DENTZ

Op 27 Februari 1917 was het 250 jaren geleden, dat de Zeeuwsche vlootvoogd Abraham Crynssen Suriname veroverde op de Engelschen. Het feit van den 250-jarigen band tusschen Nederland en Suriname werd in Nederland niet gevierd, zooals in 1934 ten aanzien van Curaçao het geval was, toen door een plechtige samenkomst en een tentoonstelling Curaçao onder de aandacht van duizenden kwam; er werd in 1917 zelfs geen commissie in Nederland opgericht om een herdenking voor te bereiden.

Toch ging deze gebeurtenis niet onopgemerkt voorbij. Wijlen F. E. baron Mulert, gep. kapitein ter zee, een vurig vaderlander en geschiedschrijver, noodigde mij - toen in Nederland met verlof - uit met hem een lezing over Suriname te houden in de vergadering van de Maatschappij der Nederlandsche Letterkunde te Leiden, hetgeen den 2den Februari 1917 plaats had. In deze maandvergadering hield de heer Mulert vóór de rust een voordracht: De verovering van Suriname voor 250 jaar herdacht $(27$ Februari), terwijl nà de rust de ondergeteekende een voordracht hield over: De kolonisatie van Guyana. Bovendien had ik het voorrecht in een samenkomst van de vereeniging Oost en West in de Oranje-Societeit te 's-Gravenhage een lezing over Suriname te houden, met lichtbeelden toegelicht.

Voorts schreven de heer Mulert en ik tijdig een brief aan den gouverneur van Suriname, de aandacht op de verovering van Suriname voor 250 jaar vestigende, waarin wij het verzoek deden, ter herinnering aan deze belangrijke gebeurtenis aan een straat in Suriname den naam te geven van Crynssen, aan wien noch in Nederland noch in Suriname iets herinnerde, en naar wien zelfs geen schip ooit was genoemd ${ }^{\mathbf{1}}$ ).

1) Met instemming maken wij melding van het feit, dat de Koninklijke West-Indische Maildienst een harer stoomschepen later den naam Crynssen gaf. 
Dit verzoek had het gewenschte gevolg. De Abraham Crynssendag werd met opgewektheid in Suriname gevierd. Van alle openbare gebouwen wapperde de driekleur, gelijk op nationale feestdagen gebruikelijk is. De feestdag werd geopend met een militaire reveille om zes uur des morgens, gevolgd door een militaire marsch door eenige straten. De landskantoren sloten, voor zoover de dienst het toeliet, om 12 uur en de scholen waren dien dag gesloten. Des avonds was er bal in de buitensocieteit „Het Park”. Er werden muziekuitvoeringen gegeven van 5-6 in den namiddag in den Palmentuin door het militaire muziekcorps en des avonds van half acht tot half tien op het Sivaplein door het muziekcorps der schutterij. Bovendien tusschen half negen en half tien op het Gouvernementsplein door het militaire muziekcorps, dat daarna een rondgang deed door de stad, welke met een taptoe op het Gouvernementsplein eindigde.

De gouverneur, die zich per auto dien dag op verschillende plaatsen vertoonde en overal hartelijk werd toegejuicht, had een proclamatie uitgevaardigd, welke in een buitengewoon nummer van het gouvernements-advertentieblad verscheen (G.A.B. van 28 Februari 1917 no. 19) en als volgt luidde:

Proclamatie ter gelegenheid van het 250-jarig bestaan van den band tusschen Nederland en Suriname.

Mede Ingezetenen van Suriname!

Heden ${ }^{1}$ ), den 28sten Februari, herdenken wij den dag, dat voor 250 jaren, de Kapitein ter Zee, Abraham Crynssen landde op Suriname's bodem en de Prinsenvlag plantte op de plek, die sedert dien dag Fort Zeelandia heet.

Tweehonderd vijftig jaren is Suriname met Nederland verbonden en al wijst de geschiedenis enkele tijdvakken aan, waarin de band tijdelijk was verbroken, wij weten dat niet oneenigheid tusschen de verbondenen daarvan de oorzaak was.

Een band van twee en een halve eeuw schept eene éénheid. Daar is in dien langen tijd samengroei ontstaan tusschen Nederland en Suriname.

De zeer ernstige tijdsomstandigheden, waarin de gansche we-

1) Deze datum is onjuist. Suriname werd niet op 28 maar op 27 Februari door Crynssen veroverd. Tengevolge van deze zonderlinge vergissing, onverklaarbaar, daar de heer Mulert en ik toch duidelijk hadden geschreven, dat de verovering op 27 Februari 1667 had plaats gehad, werd de herdenking in Suriname een dag te laat gevierd. 
reld leeft, weerhouden ons om den dag van heden te maken tot een dag van luide feestvreugde. Maar de driekleur wappert en onze harten juichen.

Juichen Haar toe, onder Wier gezegend bestuur wij dezen dag in vrede mogen vieren.

Ik heb heden, daartoe uitgenoodigd door de Koloniale Staten, aan Hare Majesteit onze geëerbiedigde en geliefde Koningin telegrafisch de gelukwenschen en eerbiedige hulde der bevolking vertolkt en wederom de verzekering aangeboden van de gevoelens van oprechte liefde, trouw en aanhankelijkheid, welke Harer Majesteits Onderdanen in dit gewest steeds bezielen.

Harer Majesteits Regeering gaf blijk van belangstelling door de aanbieding van oprechte wenschen voor het welzijn van de kolonie en hare bewoners.

Herdenkt wat Oranje ook voor Suriname tot den huidigen dage geweest is!

Herdenkt wat Nederland voor Suriname deed!

En spreekt met mij den hartelijken wensch uit dat wij onder Oranje, met Nederland vereend, gelukkige tijden mogen tegemoet gaan.

In het feestelijk en dankbaar gestemde hart rijpe op dezen plechtigen dag de besliste wil om allen, éénsgezind, de kracht te wijden aan het welzijn van Suriname, opdat in den vierbond met Nederland, met Curaçao en met Nederlandsch-Indië, ook van Suriname helder licht uitstrale in den glans die het Koninkrijk der Nederlanden omgeeft !

Tezamen schrijden wij voort.

Op onzen weg klinke luide:

Voorspoed voor Nederland!

Voorspoed voor Suriname!

Voorspoed voor het geheele Koninkrijk!

Leve de Koningin!

Paramaribo, 28 Februari 1917.

De Gouverneur van Suriname, Staal.

Tusschen den gouverneur eenerzijds, de Koningin en den minister van koloniën anderzijds werden de volgende telegrammen gewisseld:

1. Het telegram van den Gouverneur aan H. M. de Koningin luidde als volgt: 
Her Majesty the Queen

Hague

Commemorating two and half centuries union between Holland and Surinam inhabitants Surinam respectfully present Your Majesty their homage and heartiest wishes for felicity Your Majesty and Royal Family whilst Your Majesty's subjects myself included seize opportunity to renew assurance of sincerest gratitude love faith and devotion

Governor Staal.

(H. M. de Koningin

Den Haag

De band van twee en een halve eeuw tusschen Holland en Suriname herdenkende, bieden de bewoners van Suriname eerbiedig Uwe Majesteit hunne hulde en hartelijkste gelukwenschen voor Uwe Majesteit en de koninklijke familie aan, terwijl Uwer Majesteits onderdanen, met inbegrip van mijzelven, de gelegenheid aangrijpen, de verzekering te hernieuwen van de oprechtste dankbaarheid, liefde, trouw en toewijding

Gouverneur Staal.)

2. De Koningin seinde terug:

C'est avec vive satisfaction que je me souviens de la date d'aujourdhui. Je vous assure que mes pensées se joignent à celles de la colonie Suriname

Wilhelmina.

(Met levendige vreugde herinner ik mij de datum van heden. Ik verzeker u, dat mijne gedachten zich vereenigen met die der kolonie Suriname.)

\section{Sa Majesté la Reine}

La Haye

3. Je me permets respectueusement de remercier Votre Majesté pour la haute sympathie qu'Elle a daigné témoigner pour ce jour

Gouverneur Staal.

(H. M. de Koningin

Den Haag

Ik neem eerbiedig de vrijheid Uwe Majesteit te bedanken voor de hooge belangstelling welke het Haar behaagd heeft te toonen voor dezen dag

Gouverneur Staal.) 
4. De Minister van Koloniën verzond aan den Gouverneur het volgende telegram:

Governor Paramaribo

At two and half centuries jubilee union Holland and Surinam Her Mayesty's government expresses sincere wishes for prosperity colony and inhabitants

(Gouverneur Paramaribo

Minister Pleyte.

Bij het jubileum van twee en een halve eeuw van den band tusschen Holland en Suriname spreekt H. M's Regeering de oprechte wenschen voor de welvaart van de kolonie en hare inwoners uit.

Minister Pleyte.)

5. Hierop antwoordde de Gouverneur met het volgende:

Colonies Hague

In colony's name I present Her Majesty's Government heartiest thanks for good wishes which I reciprocate adding expression sincerest gratitude for Holland benevolence and Governments undiminished care in actual troublesome circumstances

Gouvernor Staal.

(Koloniën Den Haag

In de naam van de kolonie bied ik H. M's Regeering hartelijkste dank voor de goede wenschen, welke ik op mijn beurt weder aanbied onder toevoeging van de uitdrukking van de oprechtste dankbaarheid voor Hollands welwillendheid en de onverminderde zorg van de Regeering in de huidige moeilijke omstandigheden

Gouverneur Staal).

Eindelijk besloot de gouverneur de nieuwe verbindingsweg tusschen het Gouvernementsplein en het voorfort Zeelandia den naam Abraham Crynssenweg te geven. Aangezien deze weg niet eerder gereed was, had de officiëele opening eerst den 22sten December plaats. De militairen maakten om kwart voor zeven een wandeling door de stad en werden om acht uur aan de Tamarindelaan opgesteld, om vandaar het fort binnen te marcheeren langs den nieuwen weg onder de tonen van den Abraham Crynssenmarch, door frater Anselmus op muziek gezet. De gouverneur vereerde deze plechtigheid met zijn tegenwoordigheid. Van half zeven tot acht uur gaf de militaire kapel een concert in het voorfort, waarbij de nieuwe weg met lampions werd verlicht. 
Naar aanleiding van deze Abraham Crynssenherdenking stelde ik een lijst samen van tijdschriften en kranten, die over deze herdenking geschreven hebben zoowel in Nederland als in Suriname, en bood die, gevolgd door een aanvullingslijst, mede namens baron Mulert aan den gouverneur van Suriname aan, die bij resoluties van 27 Juni 1918 no. 2154 en 19Februari 1919 no. 632 bepaalde, dat een exemplaar in de Koloniale Bibliotheek te Paramaribo, in de bibliotheek van het Schoolmuseum, de GouvernementsSecretarie en het Departement van Onderwijs zou worden geplaatst.

Ik heb deze lijst, thans aangevuld en verbeterd, in alphabetische volgorde omgewerkt en meen, dat het nut kan hebben haar vast te leggen - met de voorgaande bijzonderheden — in het eenige over Suriname bestaande West-Indische tijdschrift. Zij volgt hieronder:

1. Amsterdammer, weekblad voor Nederland (De). Surinamenummer van 24 Februari 1917, no. 2070, met artikelen van prof. Van Hamel, dr. C. Lely, W. H. D. baron van Asbeck, mr. dr. C. F. Schoch, prof. dr. H. Brugmans, A. G. van Hamel, Herm. J. Jacobs, met een teekening van Johan Braakensiek „Suriname na 250 jaar”, Suriname-Asschepoester: „Wanneer komt dan een Prins, om mij naar 't bal te leiden?"

2. Alsvoren van 7 April 1917 no. 2076 met artikelen van mr. P. Hofstede Crull en dr. J. Dekker.

3. Bijdragen en mededeelingen van het Historisch genootschap te Utrecht. 39ste deel (1918) met bijdrage: Suriname vóór de verovering door Abraham Crynssen, door Fred. Oudschans Dentz.

4. Alsvoren 40ste deel (1919) met bijdragen: Stukken vóór de verovering van Suriname, door Fred. Oudschans Dentz.

5. Bijdragen voor vaderlandsche geschiedenis en oudheidkunde. 1917 Vde Reeks, deel V, Afl. I. Bladvulling. Abraham Crynssen, door F. E. baron Mulert.

6. Encvclopaedie van Nederlandsch West-Indië. Voorrede van de Uitgevers Martinus Nijhoff en N.V. E. J. Brill op 27 Februari 1917.

7. Gouvernements-advertentieblad. Buitengewoon nummer op $\left.28^{1}\right)$ Februari 1917, no. 19 met: Proclamatie van den Gouverneur van Suriname ter gelegenheid van het 250-jarig bestaan van den band tusschen Nederland en Suriname.

1) Zie noot op blz. 277. 
8. Haagsche Post, (De) 24 Februari 1917, no. 165, met artikel: De Verovering van Suriname 1667-1917.

9. Koloniaal Tijdschrift, (Het) Maart 1917, no. 3, met artikel: De kolonisatie van Guyana, door Fred. Oudschans Dentz. Lezing gehouden in de vergadering van de Maatschappij der Nederlandsche Letterkunde op 2 Februari 1917.

10. Morks Magazijn. Maart 1917 no. 3, met artikel: Suriname 250 jaar Nederlandsche Kolonie, door C. van Son (Geilll.).

11. Nederlandsche Zeewezen (Het) 16 April no. 8, 1 Mei no. 9 en 1 Juni 1917 no. 11, met artikel: De Scheepvaart naar en in de West, door Fred. Oudschans Dentz (Geill.).

12. Neerlandia. Maandblad van het Algemeen Nederlandsch Verbond. Februari 1917 no. 2, met artikel: Suriname 250 jaar Nederlandsch, 1667-27 Februari-1917, door Fred. Oudschans Dentz.

13. Alsvoren. Maart 1917, no. 3, met artikel: Suriname herdacht, door Fred. Oudschans Dentz, (Geilll.).

14. Alsvoren. Juni 1917, no. 6, met artikel: Suriname, in de rubriek West-Indië.

15. Nieuwe Rotterdamsche Courant, (De). 27 Februari 1917. Ochtendblad A. met artikel (feuilleton): Een Zeeuwsch bedrijf in 1667, door E. J. B. Luitink.

16. Alsvoren. 27 Februari 1917. Avondblad B. met Hoofdartikel: Suriname.

17. Onderwijs, (Het). Orgaan van het Surinaamsch Onderwijzersgenootschap. 28 Februari 1917, no. 18, met artikel: Abraham Crynssendag 28 Februari 1917 door K(essler).

18. Onze Eeuw. Maart 1917, no. 3, met artikel: De Verovering van Suriname voor 250 jaar herdacht (27 Februari 1667), door F. E. baron Mulert. Lezing gehouden in de vergadering van de Maatschappij der Nederlandsche Letterkunde op 2 Februari 1917.

19. Oost en West. 1 Maart 1917, no. 9 met artikel: Suriname 250 jaar Nederlandsch 1667-27 Februari-1917, door Fred. Oudschans Dentz.

20. Alsvoren. 8 Maart 1917, no. 10. met artikel: Suriname herdacht (nabetrachting), door Fred. Oudschans Dentz.

21. Alsvoren. 29 Maart 1917, no. 13, met artikel: Suriname 250 jaar Nederlandsch (in Oost en West-Indisch Literatuuroverzicht).

22. Op den uitkijk. Weekblad voor Suriname 24 Februari 1917, no. 107: De brief van de Week. 
23. Orang Peladang. 15 Maart 1917, no. 6, met artikel: Suriname 1667 tot 1917, door Sernam Boy.

24. Panorama. 7 Maart 1917 no. 36, met gedenkblad: Het 250-jarig bestaan onzer kolonie Suriname (Geill.).

25. Prins, $(D e) .10$ Maart 1917, no. 35, met artikel: De Kolonie Suriname 1667-27 Februari 1917 (Geilll.).

26. Spiegel, $(D e)$. Weekillustratie voor het Christelijk Gezin. 24 Februari 1917, no. 21. met artikel: Suriname 250 jaar Nederlandsch, 27 Februari 1667-27 Februari 1917.

27. Stemmen des Tijds. April 1917 met artikel: Suriname's Heden en Toekomst, door mr. dr. C. F. Schoch.

28. Suriname. Koloniaal Nieuws- en Advertentieblad 13 Februari 1917, no. 13 met artikel: Een herdenkingsdag, $28 \mathrm{Fe}-$ bruari 1667, door J. R. Tomson.

29. Surinamer, $(D e) .25$ Februari 1917 no. 16 met hoofdartikel: Een Herdenkingsdag, en van 1 Maart 1917 no. 17 met hoofdartikel: De Herdenkingsdag.

30. Timehri. Journal of the Royal Agricultural and Commercial Society of British Guiana. Vol. VI. September 1919. Colonisation Number. Surinam as a Dutch Possession. 1667-Februari-1917, door Fred. Oudschans Dentz en The Celebration of the Anniversary by the Dutch on February 28th 1917, door Fred. Oudschans Dentz.

31. Vaderland, (Het). 26 Februari 1917, Avondblad, met artikel: Uit de eerste Geschiedenisjaren van Suriname 1667-27 Februari-1917, door Herm. J. Jacobs.

32. Alsvoren. 27 Februari 1917, Avondblad, met artikel: Suriname, door mr. D. Fock.

33. Weekblad voor Indie. 20 Mei 1917, met hoofdartikel door Johan Koning.

34. West, $(D e)$. 27 Februari 1917, no. 779 met hoofdartikel: Crynssendag.

Nog zij hier vermeld, dat er een Crynssen-nummer van De

Periscoop, Algemeen Weekblad voor Suriname, verscheen op 28 Februari 1925, no. 18 met verschillende artikelen van Fred. Oudschans Dentz.

Tenslotte herinneren wij aan de te waterlating van de mijnveger Abraham Crynssen op 23 September 1936 op de werf Gusto te Schiedam, gebouwd in opdracht van het departement van Defensie. 